\title{
Clinical and angiographic prediction of cardiac death after coronary artery bypass graft surgery
}

Heikki V Huikuri, Sinikka Yli-Mäyry, K E Juhani Airaksinen, Markku J Ikäheimo, Markku K Linnaluoto, Juha T Takkunen

Abstract
Objectives-To study the risk factors for cardiac mortality after coronary artery bypass graft surgery.

Design and Setting-Follow up study of patients who had undergone coronary artery bypass graft surgery at the University Hospital of Oulu, Finland.

Patients and Interventions-339 consecutive patients who underwent cardiac catheterisation three months after bypass surgery.

Main Outcome Measures -Incidence of cardiac deaths during the follow up period of five years and predictive value of clinical and angiographic variables for subsequent cardiac mortality.

Results-The incidence of cardiac deaths was $5 \cdot 1 \%$, and $81 \%$ of these were sudden deaths. The postoperative ejection fraction was significantly lower in the patients with subsequent cardiac death than in the survivors $(p<0.001)$, and their left ventricular end systolic and end diastolic volumes were higher ( $p<0.001$ and $p<0.05$ respectively). The incidence of cardiac deaths was $43 \%$ in the patients with a postoperative ejection fraction of $<40 \%$. The myocardial jeopardy index after surgery and the rate of graft patency were not significantly different in the survivors and patients who died. The only clinical factors that were different between the groups were postoperative use of diuretics $(p<0.001)$ or digitalis $(p=0.02)$. After adjustment for other prognostic variables by the proportional hazards method, a low postoperative ejection fraction remained significant as a predictor of the relative risk of cardiac mortality five years after operation (p $<0.01)$.

Conclusions-Patients with angiographic evidence of impaired left ventricular function after bypass surgery are still at relatively high risk of dying suddenly, but myocardial ischaemia due to incomplete revascularisation is not strongly associated with an increased risk of cardiac mortality. Conventional clinical methods do not seem to be helpful for identifying patients with an increased risk of cardiac death after bypass surgery.
Many patients with ischaemic heart disease are presently treated by coronary artery bypass graft surgery to improve survival and relieve symptoms. Coronary artery bypass surgery may have beneficial effects on survival in those patients who have signs of impaired left ventricular function or severe coronary artery disease or both in preoperative angiographic studies. ${ }^{1-3}$ Revascularisation effectively abolishes myocardial ischaemia and left ventricular function may also be altered after surgery. ${ }^{45}$ The risk profile for the patients may thus change significantly after bypass operation.

We have prospectively followed up 339 patients in whom clinical and angiographic features had been assessed before and three months after bypass surgery. Our main purpose was to evaluate the postoperative risk factors for subsequent cardiac mortality during the five years after operation. Knowledge of these risk factors could allow new strategies to be developed to improve the survival of patients after revascularisation surgery.

\section{Methods}

PATIENTS

The patient population consisted of 339 consecutive patients who were treated by coronary artery bypass graft surgery in our department and who gave their informed consent for recatheterisation at three months after operation. They were subsequently followed up for five years. Eight patients had refused recatheterisation, and were excluded from the consecutive series. Tables 1 and 2 show the preoperative and postoperative clinical features of the patients.

CARDIAC CATHETERISATION AND ANGIOGRAPHIC STUDIES

The preoperative and postoperative selective coronary artery and bypass graft angiograms were performed on multiple projections including caudal and cranial views and were interpreted as described earlier. ${ }^{6}$ Luminal narrowings of the coronary arteries or bypass grafts $>50 \%$ were regarded as significant lesions. Left ventricular volumes were quantified by biplane left ventricular cineangiography. ${ }^{6}$ The ejection fraction was calculated by the biplane area-length method.

We used the myocardial jeopardy index to quantify the extent of the myocardium at risk 
Table 1 Preoperative and perioperative data

\begin{tabular}{|c|c|c|}
\hline Data & Alive $(n=316)$ & Cardiac death $(n=17)$ \\
\hline \multicolumn{3}{|c|}{ Clinical data } \\
\hline $\begin{array}{l}\text { Age }(\text { mean }(S D) \text { yr }) \\
\text { Sex }(F / M) \\
\text { NYHA class: }\end{array}$ & $\begin{array}{l}50(7) \\
37 / 279\end{array}$ & $\begin{array}{l}51 \quad(9) \\
2 / 15\end{array}$ \\
\hline $\begin{array}{l}\text { NYHA class: } \\
\text { I } \\
\text { II } \\
\text { III } \\
\text { IV } \\
\text { Symptoms of CHF } \\
\text { Previous MI: }\end{array}$ & $\begin{aligned} 6 & (0 \text { to } 4 \%) \\
45 & (10 \text { to } 19 \%) \\
183 & (53 \text { to } 64 \%) \\
82 & (21 \text { to } 31 \%) \\
63 & (15 \text { to } 24 \%)\end{aligned}$ & $\begin{array}{lr}1 & (0 \text { to } 29 \%) \\
1 & (0 \text { to } 29 \%) \\
6 & (14 \text { to } 62 \%) \\
4 & (7 \text { to } 50 \%) \\
4 & (7 \text { to } 50 \%)\end{array}$ \\
\hline $\begin{array}{l}\text { Previous MI: } \\
0 \\
1 \\
2 \text { Or more } \\
\text { Medication: }\end{array}$ & $\begin{aligned} 156 & (45 \text { to } 56 \%) \\
114 & (31 \text { to } 42 \%) \\
46 & (10 \text { to } 20 \%)\end{aligned}$ & $\begin{array}{ll}6 & (14 \text { to } 62 \%) \\
8 & (23 \text { to } 72 \%) \\
3 & (4 \text { to } 43 \%)\end{array}$ \\
\hline $\begin{array}{l}\text { Medication: } \\
\text { Digitalis } \\
\text { Diuretic } \\
\beta \text { Blocking agent } \\
\text { Calcium antagonist } \\
\text { Antiarrhythmic drug } \\
\text { Electrocardiogram: }\end{array}$ & $\begin{aligned} 109 & (30 \text { to } 41 \%) \\
86 & (22 \text { to } 32 \%) \\
282 & (88 \text { to } 93 \%) \\
166 & (48 \text { to } 59 \%) \\
12 & (2 \text { to } 7 \%)\end{aligned}$ & $\begin{aligned} 8 & (23 \text { to } 72 \%) \\
10 & (33 \text { to } 82 \%)^{\star} \\
13 & (50 \text { to } 93 \%) \\
12 & (44 \text { to } 90 \%) \\
2 & (1 \text { to } 36 \%)\end{aligned}$ \\
\hline $\begin{array}{l}\text { Electrocardiogram: } \\
\text { Q waves } \\
\text { Bundle branch block } \\
\text { LVH }\end{array}$ & $\begin{aligned} 106 & (30 \text { to } 41 \%) \\
20 & (4 \text { to } 10 \%) \\
12 & (2 \text { to } 7 \%)\end{aligned}$ & $\begin{array}{ll}9 & (28 \text { to } 77 \%) \\
2 & (1 \text { to } 36 \%) \\
1 & (0 \text { to } 29 \%)\end{array}$ \\
\hline $\begin{array}{l}\text { x Ray film: } \\
\text { Cardiac enlargement } \\
\text { Congestion }\end{array}$ & $\begin{aligned} 101 & (27 \text { to } 38 \%) \\
7 & (1 \text { to } 5 \%)\end{aligned}$ & $\begin{array}{ll}8 & (23 \text { to } 72 \%) \\
0 & (0 \text { to } 20 \%)\end{array}$ \\
\hline \multicolumn{3}{|c|}{ Angiographic data } \\
\hline $\begin{array}{l}\text { Coronary angiogram: } \\
1 \text { Vessel disease } \\
2 \text { Vessel disease } \\
3 \text { Vessel disease } \\
\text { Left ventriculogram: }\end{array}$ & $\begin{aligned} 38 & (8 \text { to } 16 \%) \\
97 & (25 \text { to } 36 \%) \\
181 & (53 \text { to } 64 \%)\end{aligned}$ & $\begin{array}{rr}0 & (0 \text { to } 20 \%) \\
6 & (14 \text { to } 62 \%) \\
11 & (38 \text { to } 86 \%)\end{array}$ \\
\hline $\begin{array}{l}\text { Left ventriculogram: } \\
\text { LVEDP }(\mathrm{mm} \mathrm{Hg}) \\
\text { LVESVI }\left(\mathrm{ml} / \mathrm{m}^{2}\right) \\
\text { LVEDVI }\left(\mathrm{ml} / \mathrm{m}^{2}\right) \\
\text { LVEF }(\%) \\
\text { Contractility score: }\end{array}$ & $\begin{array}{ll}14(\text { SD } 6) & (13 \text { to } 15) \\
34 \text { (SD 23) } & \text { (31 to 37) } \\
83 \text { (SD 60) } & \text { (76 to 90) } \\
58(\text { SD 11) } & \text { (57 to 59) }\end{array}$ & $\begin{array}{ll}20 \text { (SD 6) } & (17 \text { to } 23)^{\star \star} \\
49 \text { (SD 22) } & (38 \text { to } 60)^{\star} \\
93 \text { (SD 24) } & (81 \text { to } 105) \\
49(\text { SD 13) } & (42 \text { to } 56)^{\star}\end{array}$ \\
\hline $\begin{array}{l}\text { Contractility score: } \\
7-8 \\
9-11 \\
12 \text { or more }\end{array}$ & $\begin{aligned} 236 & (71 \text { to } 81 \%) \\
41 & (9 \text { to } 17 \%) \\
39 & (8 \text { to } 16 \%)\end{aligned}$ & $\begin{array}{ll}7 & (18 \text { to } 67 \%) \\
6 & (14 \text { to } 62 \%) \\
4 & (7 \text { to } 50 \%)\end{array}$ \\
\hline \multicolumn{3}{|c|}{ Perioperative data } \\
\hline $\begin{array}{l}\text { No of inserted grafts } \\
\text { Use of IMA graft } \\
\text { Q wave infarction } \\
\text { Other complications } \\
\text { Aortic cross clamp (min) } \\
\text { Maximal creatine kinase } \mathrm{MB}(\mathrm{U} / \mathrm{l})\end{array}$ & $\begin{array}{l}3 \cdot 0(\text { SD } 1 \cdot 0)(2 \cdot 9-3 \cdot 1) \\
107 \quad(30 \text { to } 39 \%) \\
10(2 \text { to } 6 \%) \\
108(29 \text { to } 40 \%) \\
84(\text { SD } 25) \quad(81 \text { to } 87) \\
67(\text { SD } 88) \quad(57 \text { to } 77)\end{array}$ & $\begin{array}{l}3 \cdot 3(\text { SD } 0.9)(2.6 \text { to } 4 \cdot 0) \\
2(1 \text { to } 36 \%) \\
2 \quad(1 \text { to } 36 \%) \\
8(23 \text { to } 72 \%) \\
91(\text { SD } 21) \quad(80 \text { to } 102) \\
79(\text { SD } 66) \quad(45 \text { to } 113)\end{array}$ \\
\hline
\end{tabular}

${ }^{\star} \mathrm{p}<0.05 ;{ }^{\star \star} \mathrm{p}<0.01$.
$95 \%$ Confidence intervals for the means and frequencies in parenthesis.

$95 \%$ Confidence intervals for the means and frequencies in parenthesis. CHF, congestive heart failure; MI, myocardial infarction; LVH, left ventricular hypertrophy; LVEDP, left ventricular end LVEF, left ventricular ejection fraction; IMA, internal mammary artery.

of ischaemia after bypass surgery. Anterior myocardial jeopardy was when the stenotic $(>50 \%)$ left anterior descending coronary artery without a patent bypass graft was supplying a normal or hypokinetic anterior or septal left ventricular wall segements, or both. Inferior jeopardy was present when the stenotic right coronary artery without a patent bypass graft was supplying a normal or hypokinetic ("viable") inferior left ventricular segment; and posterior jeopardy was when the stenotic left circumflex coronary artery without a patent bypass graft was supplying a viable posterior left ventricular segment. The range of the jeopardy index was from 0 (no jeopardy) to 3 (all segments in jeopardy).

The left ventricle was divided into five segments on the right anterior oblique projection (anterobasal, anterolateral, apical, diaphragmatic, and posterobasal), and into two segments on the left anterior oblique projection (posterobasal, septal). Each segment was coded for wall motion as normal ( 1 point), hypokinetic ( 2 points), akinetic ( 3 points), or dyskinetic (4 points). The sum of the points for each segment was used as a scoring system for left ventricular contractility as follows: 7 or 8 points, normal or mild contraction abnormality; 9-11, moderate contraction abnormality; more than 12 , severe contraction abnormality.

\section{PERIOPERATIVE DATA}

Aortic cross clamping time and maximal creatine kinase $\mathrm{MB}$ release into plasma after operation were determined in each patient. Perioperative complications, including low output syndrome, reoperation due to bleeding, electrocardiographic conduction disturbances, atrial fibrillation, and signs of post-pericardiotomy syndrome were also noted. Perioperative myocardial infarction was defined as new occurrence of $Q$ waves in the electrocardiogram.

\section{FOLLOW UP}

A questionnaire was sent to all patients. If a complete answer was not received the patients or their relatives or primary physicians were contacted by telephone. The cut off point for 
Cumulative survival curves (solid lines) (95\% confidence intervals as dotted lines) of the patients with $a$ postoperative ejection fraction (EF) of $<40 \%$ and those with an $E F$ of $>40 \%$. The survival curves were significantly different between the groups at five years after coronary artery bypass surgery $(p<0.001)$.

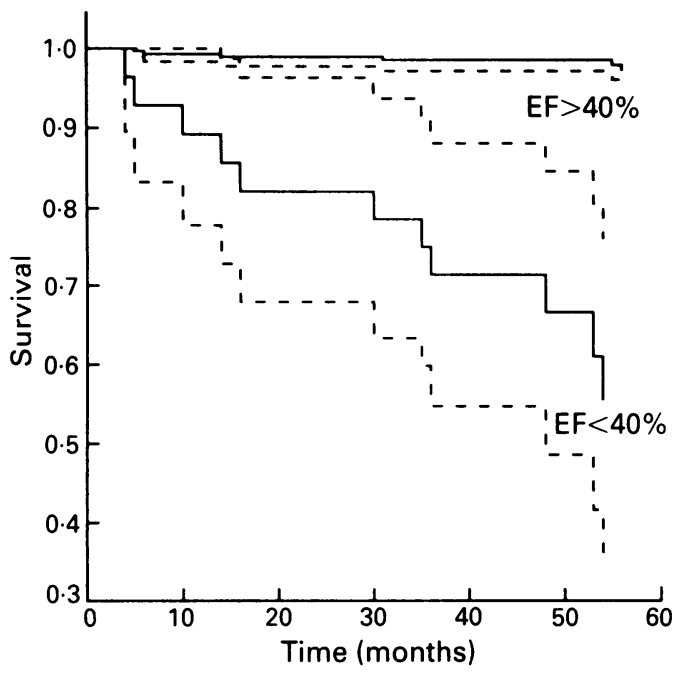

POSTOPERATIVE DATA

Treatment with digitalis and diuretic drugs was more common three months after surgery in the patients who died than in the survivors. Clinical heart failure tended to be less common in survivors ( $p=0.05$ ), though the functional class did not differ significantly between the groups (table 2 ).

Postoperative left ventricular volumes and left ventricular end diastolic pressures were significantly higher and ejection fractions lower in those who died, and abnormalities of left ventricular wall motion were more common. The left ventricular end systolic volume index increased from a mean (SD) of 49 (22) to 65 (38) $\mathrm{ml} / \mathrm{m}^{2}(\mathrm{p}<0.05)$ and the ejection fraction decreased from 49 (13) to 40 (15)\% (p < 0.05) in patients who died of cardiac causes after surgery, whereas left ventricular function remained unchanged in the survivors. The postoperative myocardial jeopardy index did not differ between the groups, nor did the rate of graft patency. Twenty eight patients had an ejection fraction $<40 \%$ after bypass surgery, and $12(43 \%)$ of these patients died of cardiac causes during the follow up. Only five patients with subsequent cardiac death had a preoperative ejection fraction $<40 \%$. Cumulative survival was significantly lower in the patients in whom the postoperative ejection fraction was $<40 \%$ than in those in whom it was $>40 \%$ (figure). Eleven ( $31 \%$ ) of the patients with a postoperative end systolic volume index $>50 \mathrm{ml} / \mathrm{m}^{2}$ after surgery died from cardiac causes.

After adjustment for prognostic variables by

Table 3 Cox regression analysis and proportional hazard functions

\begin{tabular}{llll}
\hline Covariate & $\begin{array}{l}\text { Five year } \\
\text { coefficients }\end{array}$ & $\begin{array}{l}\text { Standard error } \\
\text { of coefficients }\end{array}$ & p Value \\
\hline Angiographic: & & & \\
$\quad$ Postoperative EF & 0.08 & 0.03 & 0.001 \\
₹1 occluded graft & 0.19 & 0.53 & 0.7 \\
Clinical: & & & \\
Angina pectoris & 0.90 & 0.82 & 0.28 \\
Symptoms of CHF & 0.15 & 0.55 & 0.78 \\
Digitalis usage & 0.24 & 0.69 & 0.7 \\
Diuretic usage & 1.65 & 0.69 & 0.02 \\
\hline
\end{tabular}

EF, ejection fraction; $\mathrm{CHF}$, congestive heart failure. the proportional hazards method, a low postoperative ejection fraction remained significant in predicting the risk of cardiac mortality five years after surgery (table 3 ).

\section{Discussion}

The angiographically determined degree of left ventricular dysfunction after coronary artery bypass surgery was most closely associated with an increased risk of cardiac death during the first five years after operation. Although the largest survival benefit from revascularisation has been reported in patients with reduced preoperative ejection fraction, ${ }^{7-9}$ the present data show that the risk of cardiac death still remains relatively high in patients with impaired ventricular function after revascularisation. The state of left ventricular function has been identified as the most important risk factor for cardiac mortality in almost all surveys of prognostic indicators in patients with coronary artery disease. ${ }^{10-14}$ So far there has been little information, however, on the prognostic importance of left ventricular function assessed after the abolition of ischaemia by revascularisation. The contribution of reversible ischaemic left ventricular dysfunction to a low preoperative ejection fraction in previous studies has been largely unknown, and thus probably accounts for a beneficial effect of revascularisation on survival. Some patients may have continuing myocardial ischaemia which results in abnormalities of wall motion at the time of the preoperative ventriculogram and all abnormalities may not necessarily reflect irreversible scarring of the left ventricle.

Left ventricular function had deteriorated after bypass surgery in many patients who subsequently died. Thus perioperative myocardial damage had occurred in these patients. Perioperative infarction, incomplete revascularisation, acute graft occlusions, technical difficulties leading to long aortic cross clamping times, and inadequate myocardial protection may all give rise to impairment of ventricular function. Perioperative $Q$ wave infarctions were fairly uncommon, but new abnormalities of left ventricular contraction were detected in five of 17 patients who later died. It is obvious that small perioperative infarctions or diffuse myocardial damage often remain undetected after operation. Some institutional factors such as surgical and myocardial preservation techniques may influence the outcome after operation. In any case, the present data emphasise the importance of developments in protection from perioperative myocardial damage, especially with high risk patients in whom left ventricular contractility is impaired before operation.

Conventional clinical methods after surgery were not very helpful for identifying patients who would subsequently die of cardiac causes. The functional state of the patients after operation did not reliably identify the increased risk of cardiac death, although those who later died tended to have symptoms of heart failure more often than those who survived. Previous research had indicated that the severity of 
symptomatic heart failure correlates poorly with the ejection fraction or other indices of left ventricular function. ${ }^{1516}$ Thus impaired left ventricular function may not be easy to recognise clinically despite its adverse prognostic significance. The patients who died were more likely to be taking digitalis and diuretic drugs than those who survived. This association may not be related to the medications themselves, but rather reflects more frequent episodes of past clinical heart failure.

The extent of the myocardium still at jeopardy after revascularisation was not strongly associated with increased cardiac mortality, although the small number of events prevents definite conclusions being reached, the present data suggest that myocardial ischaemia may not be crucial in the initiation of cardiac death during the first years after surgery, when the graft occlusions are infrequent. The common clinical risk factors attached to atherosclerosis, such as smoking, hypertension, and lipid profile, did not distinguish between the survivors and those who died. Atherosclerosis of bypass grafts usually accelerates later than five years after surgery, ${ }^{15}$ which perhaps explains the lack of association between the risk factors for atherosclerosis and cardiac death in this series.

Consistent with previous large trials, ${ }^{1-3}$ the incidence of cardiac deaths after bypass surgery was relatively low in this study. Despite the small number of patients who died, a high risk subgroup could be identified-namely, those with a low postoperative ejection fraction. Some variables that were not measured herefor example, data from exercise testing, ambulatory monitoring, and signal averaging electrocardiographic and invasive electrophysiological evaluation might give more information about the risk of death after operation. Most of the deaths recorded here were in fact unexpected sudden deaths. It may be that bypass surgery does not abolish the substrate for sustained ventricular tachycardia, which may play an important part in the initiation of fatal events. ${ }^{17}$ The extent to which invasive or non-invasive assessment of susceptibility to uncontrollable arrhythmias could further iden- tify a smaller group of very high risk patients within those patients with impaired left ventricular function after bypass surgery remains unknown.

This work was supported in part by the Paavo Nurm Foundation for Cardiovascular Research, Helsinki, Finland.

1 CASS Principal Investigators and Their Associates Myocardial infarction and mortality in the Coronary Artery Surgery Study (CASS) randomized trial. $N$ Engl Med 1984;310:750-5.

2 Varnauskas E, and the European Coronary Surgery Study Group. Survival, myocardial infarction, and employment status in a prospective randomized study of coronary pass surgery. Circulation 1985,72(suppl V):V-90-101

Takaro T, Hultren $\mathrm{HN}$ Lipton $\mathrm{MJ}$, Detre $\mathrm{KM}$, and Participants in the study group. The VA cooperative randomized study of surgery for coronary arterial cclusive disease II Subgroup with significant left main lesions. Circulation 1976;54(suppl 3):III-107-17.

4 Gersh BJ, Califf RM, Loop FD, Akins CW, Pryor DB Takaro TC. Coronary bypass surgery in chronic stabl ngina. Circulation 1989;79(suppl I):I-46-59.

5 Braunwald E, Rutherford JD. Reversible ischemic ventricular dysfunction: evidence of hibernating myocardium. J Am Coll Cardiol 1986;8:1467-70.

6 Huikuri HV, Korhonen UR, Linnaluoto MK, Takkunen JT. Effect of coronary artery bypass grafting on left ventricular response to isometric exercise. Am J Cardio 1984;54:514-8.

7 Alderman EL, Fisher LD, Litwin P, et al. Results of coronary artery surgery in patients with poor left ventricular function (CASS). Circulation 1983;68:785-95.

8 Passamani E, Davis KB, Gillespie MJ, Killip T, and the CASS Principal Investigators and their Associates. A randomized trial of coronary artery bypass surgery. randomized trial of coronary artery bypass surgery. Survival of patients with

9 Pigott JD, Kouchoukos NT, Oberman A, Cutter GR. Late results of surgical and medical therapy for patients with results of surgical and medical therapy for patients with coronary artery disease and depressed left
function. $J$ Am Coll Cardiol 1985;5:1036-45.

10 Nelson GR, Cohn PF, Gorlin R. Prognosis in medically treated coronary artery disease. Influence of ejection fraction compared to other parameters. Circulation 1975; 52:408-12.

11 Moss AJ. Risk stratification and survival after myocardial infarction. N Engl J Med 1983;309:331-6.

12 Hammermeister KE, DeRouen TA, Dodge HT. Variables predictive of survival in patients with coronary disease. Circulation 1979;59:421-9.

13 Massie BM, Conway M. Survival of patients with congestive heart failure: past, present, future prospects. Circulation 1987;75(suppl IV):IV11-8.

14 Groudin CM, Rampean L, Thornton JC, Engle JC, Cross FS, Schreiber H. Coronary artery bypass grafting with saphenous vein. Circulation 1989;79(suppl I):I-24-9.

15 Franciosa J. Why patients with heart failure die? Hemodynamic and functional determinants of survival. dynamic and functional determinant

16 Weschler AJ, Junod FL. Coronary bypass grafting in patients with chronic congestive heart failure. Circulation patients with chronic conge

17 Freeman S, Ruskin JN, Garan H. Effect of myocardial revascularization on inducible ventricular arrhythmias [abstract]. J Am Coll Cardiol 1989;13:174A. 